\title{
Discussion Support System for Intra-class Discussions and the Criteria for Group Making
}

\author{
Ikuo Kitagaki
}

Hiroshima University, Research Institute for Higher Education

2-12-1 Kagamiyama, Higashi-hiroshima, 739-8512, Japan

E-mail: kitagaki@hiroshima-u.ac.jp

\begin{abstract}
A computerized system has been discussed. It assists group discussion done in a classroom in the way that, first, it presents a topic with the relevant choices, second, each student selects a choice and sends it to the server, third, the server determines the groups according to the choices and other information, forth, it sends to the students' cell phone the group information with each choice, lastly, students actually make group according to the given information then start to discuss. Relating to the system, this paper describes the configuration of the proposed computer system, two aspects of group division(difference in learning and similarity in learning), the algorithm of the group division, and the execution process of actual group discussions, assisted by this system, about specific topics.
\end{abstract}

Keywords: Group division, Discussion support system, Algorithm

\section{Introduction}

Computer-assisted collaborative learning and group learning have become more popular with the development of e-learning systems. The computer system which is characterized by the algorithm for dividing one class of students into several groups for group discussion is discussed (Akahori, 1997). This computer system is used for the group division, however, it is not used in the later group discussions because the actual discussions are made as traditional face-to-face communication activities. Thus the computer system can be also called the computer-assisted, group discussion support system. Concretely speaking, this system divides one class into multiple groups according to students' answers of a discussion topic by using a specific algorithm, and each student is notified of the names of the members who belong to the same group. The students then form groups according to the notified information, exchange opinions, and discuss the topic to increase understanding. As almost all students have their own cell-phones, the computer server collects information necessary from students and distributes information to students via cell-phones.

Although the configuration of the above computer system and the algorithm of the group division are presented in this paper, the criteria of the group division has not been discussed in terms of their educational characteristics. This paper deals with not only the mathematical criteria(Kitagaki, 2008) but also the educational characteristics of two criteria: similarity in learning and difference in learning both of which are exemplified. This paper also describes the execution process of actual group discussions, assisted by this system, about specific topics.

Relating the algorithm shown in this paper, we have already discussed how to make group divisions when a test problem and the answers are the topic for discussion(Kitagaki et.al., 2007). In this case, I divided a student class based on the students' answers to the test. That is, values 1 and 0 were assigned to the right and wrong answers of the test respectively, and the class was divided into groups according to these assigned values. On the other hand, there are no concepts of correct/wrong answer in discussion. 


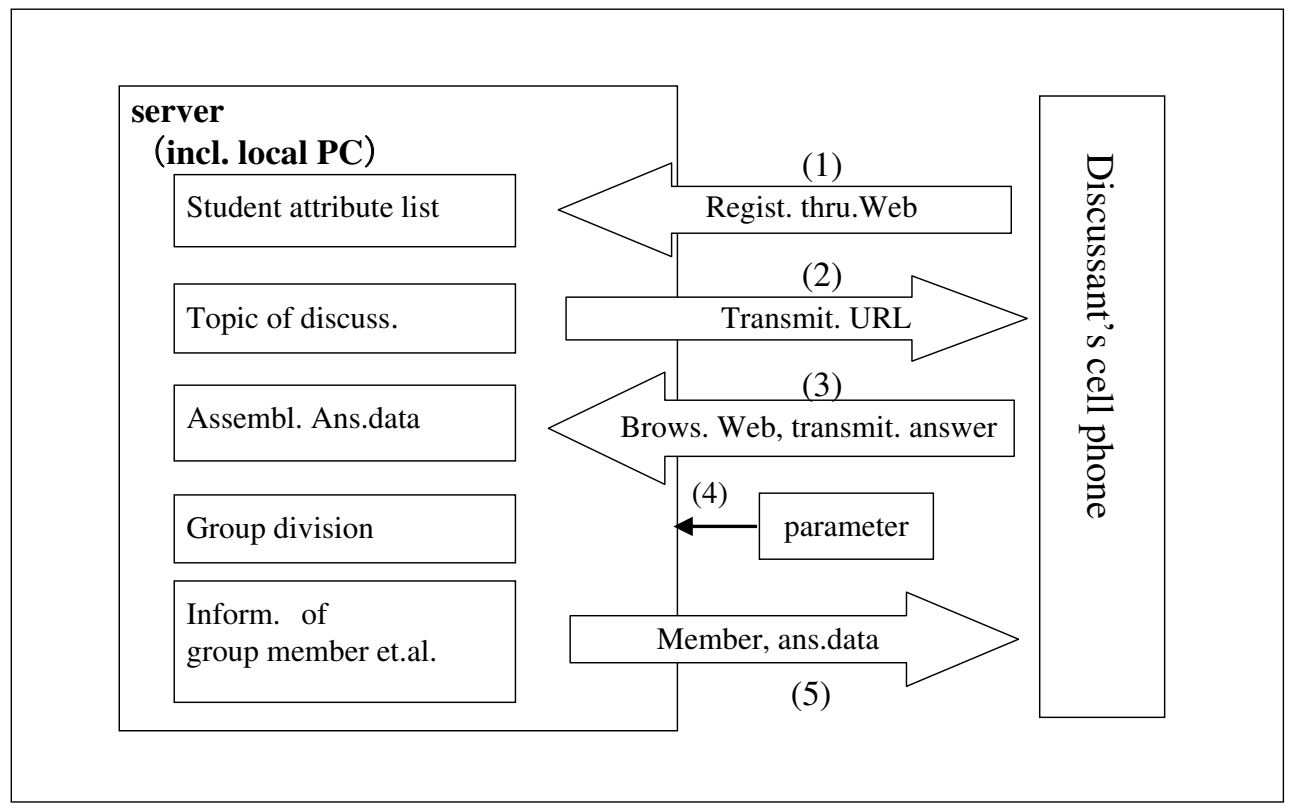

Figure 1: System configuration.

Thus the previous paper has been extended theoretically to make a revised paper this time. In the case of discussion, there could be the concepts of similar remarks and different remarks. Thus it is rational to deal with the choices so that we let them have 'distance' between 0 and 1.

\section{Discussion Support System}

Discussion support system is implementing the system flow shown in Figure 1.

1. To register student attribute list: As the initial process of the proposed system, it is necessary to register student's name, number, the mail address, sex and so forth. Among these, mail address is used for sending relevant URL and their names are used for students to know all the group member. These registrations are done on a Web page. The URL of the page is informed to all students in advance.

2. To determine a topic with its choices for discussion: There could be usually installed many topic for discussion. The teacher selects a topic among them. Then the computer sends the URL for browsing the topic to all discussants.

3. To gather the answer data as a choice: All students make an access to the URL mentioned in (2), then read the topic and the choices. They select a choice among the choices for the given topic then send it to the server. All the answer are gathered and stored in the server.

4. To make groups: The computer server makes the group division according to the student's answer as transaction data. The basic idea of the group division is explained in the later section. In the actual administration, the following parameters and the necessary information ought to be inputted prior to the group division: the value with which a topic is discussed.: the difference of choices in their contents.: the number of a group constituents

When the information of group division is obtained as a processed result, it is possible for a teacher to add, to it, remarks to each group, remarks to each individual and remarks to the all. 
5. To Inform each student of the group member, selected choice, teacher's remarks: The computer server sends to each student's mail address the group members, each answer and the remarks above if any.

Through the process above, each student is informed the name of all member which belong to the same group. Then, each group gathers somewhere inside or outside of the classroom and starts to deeply consider the topic by discussion. In the actual classroom it could be that the students don't know each other, thus, in order to make the students' group making easier, it is desirable for the server to allocate a group ID to each group and send the ID with the group information mentioned above.

\section{Two aspects of criteria for group making}

A community, in general, is made under some sort of homogeneity: similar thought, similar culture, and so forth, leading to its stable existence. On the other hand, group making for developing creative products which may be called as a small community, often needs heterogeneity such as different idea, different situation, and so forth. Thus which is valuable criterion, homogeneity or heterogeneity, will naturally depend upon the objective, characteristics and others of making the relevant human groups. Upon the consideration, I here discuss the criteria in the case of educational objectives in a classroom.

1. difference in learning: I here raise the example of regarding difference in learning in a classroom. Let us suppose that students make groups and discuss the physical problem/solution in physics. In this case it is natural to think that there could be only one correct answer/solution, which will be proved provided the relevant experiment is done. Thus if there happened to be different answers in the group, it could be valuable to makethe difference clear and discuss which idea will be correct, leading to extensive thinking a new idea. As various predictions done by the students may be converged to get a correct answer by observing the experiment for verification, fruitful discussions will be anticipated to proceed.

As an another example, a management game in a classroom will be raised where several groups compete with each other for profit in order to survive. One group may be called as a company, which generally consists of different role of constituents. If we think those constituents ought to be selected regarding different ability/characteristics, it is important to set difference in learning as a criterion for making appropriate groups.

2. similarity in learning: If student's values is important in order to get a solution as learning, there will be a case where similarity is regarded in making students' groups. Let us suppose that students plan to go abroad in a group for a learning objective thus the teacher at first surveys the place which each student wants to visit. If the places proposed in a group locate near to each other in a group, it gets possible for them to visit all the places as one trip. Consequently, I can summarize that, in the case of regarding values in order to do the group based determination, the criterion of similarity in learning ought to be used.

\section{Method of group division}

In accordance with the previous section, group division using student's choice of an answer can be made by two kinds of criterion as the followings.

1. difference in answers: Groups are made so that choices of each member may be different from those of others as much as possible. 
2. similarity in answers Group are made so that choices of each member are similar with those of others as much as possible.

Two criteria are reverse in their evaluation of 'goodness'. Thus it is enough only to explain criterion (a). As for the criterion (a), two methods have been proposed(Kitagaki, 1996; Kitagaki et.al., 1981). The proposed system in this material adopts the simpler method(Kitagaki et.al., 1981). The algorithm is outlined below.

topic sets: $M$

topic: $m_{i}(\in M)$

value of the topic: $v\left(m_{i}\right)$

group sets: $G$

relevant group: $g(\in G)$

bigness of group ' $g$ ': $|g|$

discussant(student): $x_{j}(\in g)$

selected choice: $a\left(m_{i}, x_{j}\right)$

difference of choices selected by discussant $x_{j}$

and discussant $x_{k}: d\left\{a\left(m_{i}, x_{j}\right), a\left(m_{i}, x_{k}\right)\right\}$

goodness of group division using criterion (a): $\alpha_{g}$

goodness of group division using criterion (b): $\alpha_{g}^{\prime}$

goodness per capita of group division: $\beta$

In the definition above, both of 'value of the topic' and "difference of choices selected by discussant $x_{j}$ and discussant $x_{k}$ ' are the value between 0 and 1 . The 'bigness of group $g$ " is the number of a group. The number is not always the same for all group. But its algorithm is abbreviated here. All the said variables have to be determined in advance. The 'goodness per capita of group division $\beta$ ' is determined as the following.

$$
\begin{gathered}
\alpha_{g}=\sum_{m_{i} \in M} \sum_{x_{j} \in g} v\left(m_{i}\right) \bigcup_{k}\left\{d\left\{a\left(m_{i}, x_{j}\right), a\left(m_{i}, x_{k}\right)\right\}\right\} \\
\beta=\sum_{g \in G} \alpha_{g} / \sum_{g \in G}|g|
\end{gathered}
$$

In the equation [2], group division which makes the value maximum is the optimal solution. In order to get the optimum, however, it is necessary to administrate the calculation for all the combination of groups. It is actually difficult to get it because of time for its calculation. Thus a simple method is implemented(Kitagaki et.al., 1980) as the following. Its example deals with the case that thirty discussants are divided into ten groups with three discussants each.

As the initial status, I suppose that the computer fix the discussants $x_{1}, \ldots, x_{30}$ as shown in 'n=1' Figure 2, and define the value of $\beta$ in eq.[2] as $\beta_{1}$. Then I let it compare cell1 with each cell thereafter one by one. First, let it exchange cell1 $x_{1}$ for cell $2 x_{2}$ to obtain the pattern as shown in ' $n=2$ ' then get the value as $\beta_{1,2}$. It is clear that $\beta_{1,2}$ is same as $\beta_{1}$ in their value. Thus there is no reason to exchange thus it ought to be withdrawn. Second, it is obvious that the exchange of $x_{1}$ and $x_{3}$ leads to the same result as above. It is cell1 and cell4 that has actual meaning of exchange because they belong to different groups in the initial pattern. If $\beta_{1}$ is bigger than(or equal to) $\beta_{1,4}$, the computer regards the pattern of ' $\mathrm{n}=4$ ' as not better pattern than the one of ' $n=1$ ' then the exchange ought to be withdrawn. On the other hand, if $\beta_{1}$ is smaller than $\beta_{1,4}$, it regards the pattern of ' $\mathrm{n}=4$ ' better than the one of ' $\mathrm{n}=1$ ' then the exchange ought to be withdrawn. On the other hand, if $\beta_{1}$ is smaller than $\beta_{1,4}$, it regards the pattern of ' $\mathrm{n}=4$ ' better than the one of ' $n=1$ ' then the exchange ought to be done to get the new pattern. Based upon the new pattern, 
it searches for a better pattern.(In the new pattern, the content of each cell is re-designated in the way that the content of cell' $i$ ' are written as $x i(i=1,30)$. It means that the new pattern is shown as $x 1 \ldots x 30$ from the leftmost column to the rightmost column.) The search for the better pattern is succeeded in the same way. If the comparison of cell1 and cell 30 has been done, cell 2 becomes the base of comparison. The exchange of cell2 and cdll3 is done as shown in the pattern of ' $n=31$ ', resulting in meaning nothing, followed by the exchange of cell 2 and cell 4 in ' $n=32$ '.

Consequently, the exchange of two cells are done in the following order, and as a result, the number of exchange becomes $870(=29 * 30)$ in all. (Actually the exchange of two cells in a group ought to be omitted.)

cell1 and cell2, cell1 and cell3, cell1 and cell4,cell1 and cell5, 'Ś,cell1 and cell29, cell1 and cell30 cell2 and cell3, cell2 and cell4, cell2and cell5, 'Ś,cell2 and cell29, cell2 and cell30 cell3 and cell4, cell3 and cell5, 'Ś,cell3 and cell29, cell3 and cell30

cell29 and cell30

\begin{tabular}{|c|c|c|c|c|c|c|c|c|c|}
\hline \multicolumn{10}{|l|}{$\mathrm{n}=1$} \\
\hline cell1 & cell2 & cell3 & cell4 & cell5 & cell6 & & cell28 & cel129 & cell30 \\
\hline \multicolumn{3}{|c|}{$\mathrm{g}_{1}$} & \multicolumn{3}{|c|}{$\mathrm{g}_{2}$} & . & \multicolumn{3}{|c|}{$\mathrm{g}_{10}$} \\
\hline $\mathrm{x}_{1}$ & $\mathrm{x}_{2}$ & $x_{3}$ & $\mathrm{x}_{4}$ & $\mathrm{x}_{5}$ & $\mathrm{x}_{6}$ & . & $\mathrm{x}_{28}$ & $\mathrm{x}_{29}$ & $\mathrm{x}_{30}$ \\
\hline \multicolumn{10}{|l|}{$\mathrm{n}=2$} \\
\hline cell1 & cell2 & cell3 & cell4 & cell5 & cell6 & & cell28 & cell29 & cell30 \\
\hline \multicolumn{3}{|c|}{$\mathrm{g}_{1}$} & \multicolumn{3}{|c|}{$\mathrm{g}_{2}$} & & \multicolumn{3}{|c|}{$\mathrm{g}_{10}$} \\
\hline $\mathrm{x}_{2}$ & $\mathrm{x}_{1}$ & $x_{3}$ & $\mathrm{x}_{4}$ & $\mathrm{x}_{5}$ & $\mathrm{x}_{6}$ & & $\mathrm{x}_{28}$ & $\mathrm{x}_{29}$ & $\mathrm{x}_{30}$ \\
\hline \multicolumn{10}{|l|}{$\mathrm{n}=4$} \\
\hline cell1 & cel12 & cell3 & cell4 & cell5 & cell6 & & cell28 & cel129 & cell30 \\
\hline \multicolumn{3}{|c|}{$\mathrm{g}_{1}$} & \multicolumn{3}{|c|}{$\mathrm{g}_{2}$} & & \multicolumn{3}{|c|}{$\mathrm{g}_{10}$} \\
\hline $\mathrm{x}_{4}$ & $\mathrm{x}_{2}$ & $\mathrm{x}_{3}$ & $\mathrm{x}_{1}$ & $\mathrm{x}_{5}$ & $\mathrm{x}_{6}$ & & $\mathrm{x}_{28}$ & $\mathrm{X}_{29}$ & $\mathrm{x}_{30}$ \\
\hline
\end{tabular}

Figure 2: The exchange of two cells(in the case that a classroom consists of thirty students).

Supposing the number of discussant to be 'n', the number of the said exchange becomes 'n(n-1)'. For each exchange, the computer gets the value of $\beta$, then the optimal group division is obtained.

If method (b) shown in the beginning of this section is implemented for group division criterion, we have only to use eq.[3] instead of eq.[1].

$$
\alpha_{g}^{\prime}=\sum_{m_{i} \in M} \sum_{x_{j} \in g} v\left(m_{i}\right) \bigcup_{k}\left\{1-d\left\{a\left(m_{i}, x_{j}\right), a\left(m_{i}, x_{k}\right)\right\}\right\}
$$

\section{The administration of discussion classroom}

As a topic for the proposed discussion, I raised a topic of career development to which most students might be relevant. The topic relates the consideration on the answer in an interview in job hunting. I administrated the classroom discussion four times. In every administration, the same topic was used. Two experimental administrations are discussed below. 
experimental 1(E1) Fifteen Hiroshima University students served as subject(twelve undergraduate students and three graduate students). Among them, nine students were science in major., Jul. 26, 2007.

experimental 2(E2) Fourteen Hiroshima University students served as subject(seven undergraduate students and seven graduate students). Among them, nine students were science in major., Nov. 11, 2007.

Table 1: A questionnaire and the answer [6]

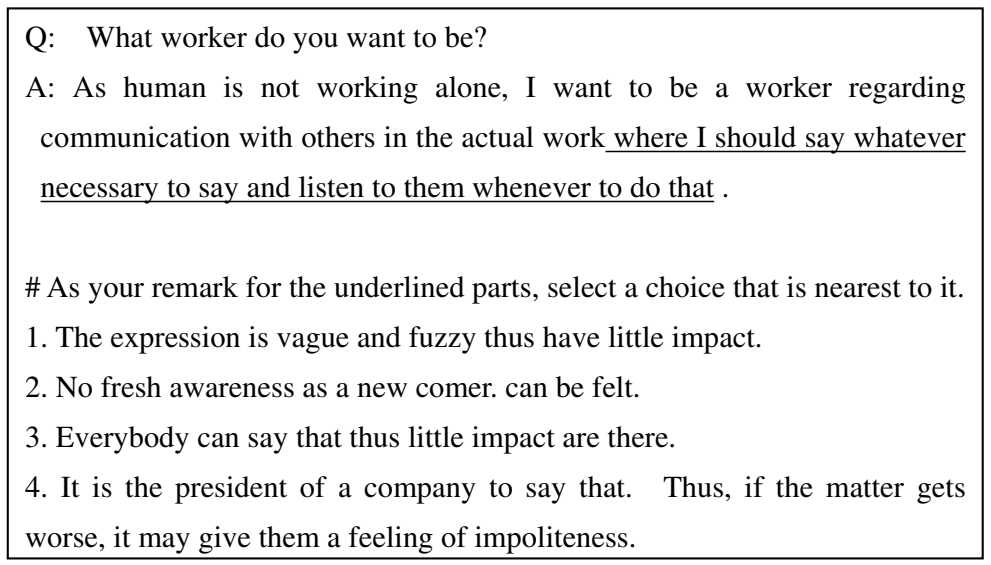

In both of E1 and E2, I used the same room and implemented the same topic which consists of two rounds, R1 and R2, that is, two 'Question-Answer' set. But the students were different in those two experiments. In either round, the question exemplified in Table 1 was used. In its actual administration, I let the students inform others in a group of the choice which each student has selected then discuss what would be a better answer for the given answer. Lastly I let them make and write a better answer then offer it as a report with of their consensus.

As most students in a group were not acquainted with each other, it was assumed that, when the information of a group member were presented in the step of Figure 1(5), it gets difficult for them to make a group. Thus ID number proper to each group was informed all the classroom, leading to easier making groups. Addition to that, as group leaders is necessary in order to facilitate the discussion well, how to determine a leader in a group was also informed them. Discussion time was set to nearly fifteen minutes, which was also informed them as a comment.

After each administration of R1 and R2, the following questionnaires have been examined to all the students.

(Influence of selecting a choice on the discussion flow)

1. I don't think that the information of a choice selection had an influence on the relevant discussion flow. In other words, discussion flow must have been the same as the one without selecting a choice.

2. I think that the information of a choice selection had an influence on the relevant discussion flow to some extent.

3. I think that the information of a choice selection had an influence on the relevant discussion flow to great extent. 
Table 2: Answer data processing of 'influence of selecting a choice'

(a)basic statistics

\begin{tabular}{|c|c|c|c|c|c|}
\hline \multirow{2}{*}{ condition } & \multicolumn{3}{|l|}{$\begin{array}{l}\text { number of students } \\
\text { selecting a choice }\end{array}$} & $X$ & $\sigma$ \\
& $(\%)$ & & \multirow{2}{*}{} \\
\cline { 2 - 5 } & 1 & 2 & 3 & & \\
\hline$\left(E_{1}, R_{1} \& R_{2}\right)$ & 0.30 & 0.57 & 0.13 & 1.90 & 0.65 \\
\hline$\left(E_{2}, R_{1} \& R_{2}\right)$ & 0.07 & 0.46 & 0.46 & 2.39 & 0.61 \\
\hline$\left(E_{1} \& E_{2}, R_{1} \& R_{2}\right)$ & 0.19 & 0.52 & 0.29 & 2.10 & 0.69 \\
\hline
\end{tabular}

Number of the students is fifteen 15 in E1, and fourteen in E2.

$X$ : average, $\sigma$ : standard deviation

(b)Z-test(using normalized distribution)

\begin{tabular}{|l|c|c|c|}
\hline \multirow{2}{*}{\multicolumn{1}{c|}{ condition }} & \multicolumn{3}{|c|}{$\mathrm{m}$} \\
\cline { 2 - 4 }$(\mathrm{E} 1, \mathrm{R} 1 \& \mathrm{R} 2)$ & $-7 \cdot 2^{*}$ & 0.86 & $9 \cdot 13^{*}$ \\
\hline (E2, R1\&R2) & $-11.9^{*}$ & $-3 \cdot 37^{*}$ & $5 \cdot 20^{*}$ \\
\hline (E1\&E2, R1\&R2) & $-12.2^{*}$ & -1.15 & $9 \cdot 94^{*}$ \\
\hline
\end{tabular}

${ }^{*}$ Hypothesis ' $\mathrm{X}=\mathrm{m}$ ' has been rejected $(\mathrm{p}<0.01), Z=\frac{(X-m) \sqrt{N}}{\sigma}$

In R1 and R2, presented topics were the same type thus those answers were added to have been statistically processed altogether. The result is shown in Table 2(a). There is also shown the result in the case that $\mathrm{E} 1$ and $\mathrm{E} 2$ were combined in their data.

From the test result shown in the table, the average choice for the questionnaire is said to be 2 (or in-between 2 and 3). It means that their average remark is that selecting a choice has an influence on the discussion flow as their awareness.

Besides the experiment shown in this material, I have done the questionnaire survey comparing criterion (a) with criterion (b) shown in the $3^{r d}$ section supposing the case that groups were divided according the criterion (b). As their awareness, it got obvious that they felt more fruitful in their discussion with variety of choices in a group than that with a similar choices.

\section{Conclusion}

This paper discussed a computerized system which assists group discussion done in a classroom. First, configuration of the system was explained. Second, two aspects of criteria for making groups, similarity in learning and difference in learning have been discussed. Third, a math. model for group division was presented. A trial of administrating a classroom discussion was done.

In its administration, a topic and the choices were presented to the students, each student selected a choice and sent it to the server, the server determined the groups, then it sent to the students the group information with each choice. From the administration, it got clear that the discussants have the awareness that letting them know their selected choice each other gave an influence on the further discussion flow. 


\section{Bibliography}

[1] Akahori K. et.al.(1997, in Japanese): The skill of university classroom teaching, Daiichi-houki, Tokyo, 142-145.

[2] Kitagaki I.,Hikita A.,Takeya M., Fujihara Y.(2007): Development of an algorithm for groupware modeling for a collaborative learning, Int'l Journal of Computers, Communication \& Control, II,1, 66-73.

[3] Kitagaki I.(1996): Evaluation of students' group using fuzzy integral, IEICE, J79-D-II,11, 18881896.

[4] Kitagaki I., Shimizu Y. and Suetake K.(1980): An instructional method which permits the students to critically discuss their own test answers, Japan Journal of Educational Technology, 5,1, 23-33.

[5] Kitagaki I.: Development of Group Division Algorithm And Discussion Support System for Intraclass Discussions, Proceedings of the $3^{\text {rd }}$ International Conference on Virtual Learning, pp.101-108, Constanta, 2008.

[6] Nakatani A.(1995, in Japanese): Expert of interviewing, Diamond Co., Tokyo.

Ikuo Kitagaki was born in Toyohashi, Japan, in 1947. He has received B.E., M.E. and Doctoral Degrees from Tokyo Institute of Technology in 1970, 1972 and 1981, respectively. He has worked in Tokyo Institute of Technology, The Institute of Vocational Training, and so forth. During the time, he has been involved in educational technology, literacy in science/technology, fuzzy science, human science, et.al.. He has been a member of the Editorial Advisory Board of the Advances in Web-based Learning(AWBL) Book Series(USA). He has received ICVL Excellence Award "Intel ${ }^{\circledR}$ Education" from the ICVL(the International Conference on Virtual Learning) Scientific Committee. 